\title{
Development of Late Continence in Bladder Exstrophy and Epispadias Patients
}

\section{Taskinen, Seppo}

2020-10

Taskinen , S , Suominen , J \& Mäkelä , E 2020 , ' Development of Late Continence in

Bladder Exstrophy and Epispadias Patients ' , Urology , vol. 144 , pp. 194-197 . https://doi.org/10.1016/j.urology.202

http://hdl.handle.net/10138/334599

https://doi.org/10.1016/j.urology.2020.06.034

cc_by_nc_nd

draft

Downloaded from Helda, University of Helsinki institutional repository.

This is an electronic reprint of the original article.

This reprint may differ from the original in pagination and typographic detail.

Please cite the original version. 


\section{Journal Pre-proof}

Development of Late Continence in Bladder Exstrophy and Epispadias Patients

Seppo Taskinen, Janne Suominen, Eija Mäkelä

PII: S0090-4295(20)30793-7

DOI: https://doi.org/10.1016/j.urology.2020.06.034

Reference: URL 22326

\section{UROLOGY}

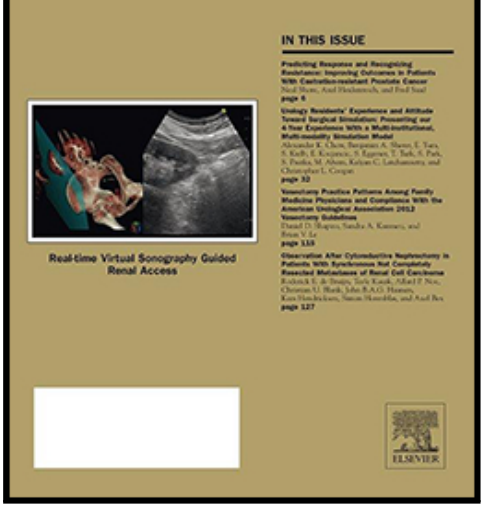

To appear in:

Urology

Received date: $\quad 6$ May 2020

Revised date: $\quad 16$ June 2020

Accepted date: 21 June 2020

Please cite this article as: Seppo Taskinen, Janne Suominen, Eija Mäkelä, Development of Late Continence in Bladder Exstrophy and Epispadias Patients, Urology (2020), doi: https://doi.org/10.1016/j.urology.2020.06.034

This is a PDF file of an article that has undergone enhancements after acceptance, such as the addition of a cover page and metadata, and formatting for readability, but it is not yet the definitive version of record. This version will undergo additional copyediting, typesetting and review before it is published in its final form, but we are providing this version to give early visibility of the article. Please note that, during the production process, errors may be discovered which could affect the content, and all legal disclaimers that apply to the journal pertain.

C) 2020 Published by Elsevier Inc. 


\section{Development of Late Continence in Bladder Exstrophy and Epispadias Patients}

Seppo Taskinen, Janne Suominen, Eija Mäkelä

Department of Pediatric Surgery, New Children`s Hospital, University of Helsinki, Helsinki, Finland

\section{Key words}

bladder exstrophy, epispadias, continence, incontinence, bladder augmentation, CIC

\section{Conflict of Interest}

None

\section{Word counts}

Abstract: 244

Manuscript: 1640

e-mails:

Seppo Taskinen: seppo.taskinen@hus.fi Janne Suominen: janne.suominen@hus.fi Eija Mäkelä: eija.makela@hus.fi

\section{Correspondence}

Seppo Taskinen, MD PhD

New Children's Hospital, University of Helsinki

Stenbäckinkatu 9

00290 Helsinki

Finland

Tel: +358 504272542

e-mail: seppo.taskinen@hus.fi; seppo.taskinen@gmail.com 


\section{ABSTRACT}

OBJECTIVES. To evaluate to what extend urinary continence develops during puberty in patients with classic bladder exstrophy (CBE) and epispadias.

METHODS. The operative database was reviewed for surgical procedures and urinary continence in all 65 CBE and epispadias patients born in 1976-2005.

Excluded were two patients who had insufficient data for evaluation.

RESULTS. Thirty-five patients with volitional voiding were incontinent at the age of 10 years, 27 had daily incontinence and eight had rare incontinence. Sixteen patients (46\%) became later fully continent without any major surgery (except Deflux ${ }^{\circledR}$ injections in three patients) or CIC treatment. Among these 16 fully continent patients there were $7 / 8$ with rare incontinence, $9 / 23$ with daily incontinence $(p=0.04)$; 3/9 males with CBE, 10/13 males with epispadias, 3/5 females with CBE and 0/4 females with epispadias ( $p=0.25$ between sex and $p=0.48$ between diagnosis). Of the 15 patients remaining incontinent, 10 had daily and five had rare incontinence episodes. The latest control was at the median age of 19 years (IQR 17-21 years). Twenty-five patients ( $40 \%$ of the whole material) were fully continent $(11 / 38(29 \%)$ with CBE and $14 / 25$ (56\%) with epispadias, $\mathrm{p}=0.04)$ and eight $(13 \%)$ had rare incontinence with volitional voiding [1/38 (3\%) with CBE and 7/25 (28\%) with epispadias].

CONCLUSIONS. Almost half of the incontinent CBE and epispadias patients with volitional voiding achieved continence after the age of 10 without major surgery. Prognosis for pubertal development of continence was best in patients with rare incontinence and in males with epispadias. 


\section{INTRODUCTION}

Despite of various operative techniques, urinary incontinence or inability to void properly remain major problems for patients operated for classic bladder exstrophy (CBE) or epispadias. Reported urinary continence rates have been between $12 \%$ and $83 \%$ in the patients with volitional voiding ${ }^{1,2}$. In many patients, the continence is achieved only with the aid of bladder augmentation or clean intermittent catheterization $(\mathrm{CIC})$ program ${ }^{3-5}$. Occasionally it is difficult to determine whether further surgery is the only chance to become continent or would the patient has still have possibility for continence later on. In our clinical practice, we have noticed that some patients tend to become continent during pubertal development. Although there are suggestions in the literature, that urinary continence may develop during puberty in patients with CBE and epispadias, this topic has not been investigated systematically ${ }^{6-8}$. In this study, we wanted to evaluate to what extent urinary continence develops during puberty in patients with CBE or epispadias in Finnish national cohort.

\section{MATERIAL AND METHODS}

The operative database of Children's Hospital, University of Helsinki was searched for patients born from 1976 to 2005 and treated for CBE or epispadias after permission of institutional review board. Patient journals were evaluated for surgical history and development of urinary continence in all 65 patients. Two patients were excluded either because of insufficient data of primary treatment or follow-up. The 
development of continence was carefully evaluated in 35 patients with volitional voiding and incontinence at the age of 10 years. Seventeen patients who had undergone bladder augmentation before the age of 16 years as well as 11 patients who were continent before the age of 10 years were excluded of the analysis concerning the pubertal development of continence (Fig.1). Incontinence was defined frequent if the patient had daily incontinence episodes and rare if the incontinence episodes were less frequent. Practically all patients with rare incontinence had more than three hour continence intervals that is the most common description for continence or social continence in these patients ${ }^{5,9}$. The need for diapers or pads was also collected from the patient journals when available.

Continuous variables are expressed as medians and interquartile ranges (IQR). Categorial variables between the groups were compared by using Fisher's exact test ( Statview ${ }^{\circledR} 5.0 .1$, SAS Institute Inc.). P-value $<0.05$ was considered significant.

\section{RESULTS}

Bladder was initially closed at the median age of 2 days (IQR 1-14) in patients with CBE and bladder neck reconstruction (BNR) was performed at the median age of 4.1 years (IQR 2.6-6.5) in patients with epispadias or CBE, except in six males with distal epispadias.

Thirty-one of 35 patients that were incontinent at the age of 10 were followed up without major surgery and four underwent BNR (Fig.1). Among 31 patients without 
BNR, sixteen patients with volitional voiding became continent without major surgery, five of them after the age of 16 years. The remaining 15 patients had either rare incontinence or daily incontinence. Development of continence was more common in patients with rare than with daily incontinence ( $7 / 8$ vs. $9 / 23$ patients, $p=0.04)$, but there was no difference between CBE and epispadias patients (6/14 vs. 10/17 patients, $p=0.48)$, (Table 1). Development of continence was similar between male and female CBE patients ( $3 / 9$ vs. $3 / 5$ patients, $p=0.58$ ), but more common in epispadias males than females ( $10 / 13$ vs. $0 / 4$ patients, $p=0.02)$. The four patients, who underwent BNR after the age of 10 , had daily incontinence. Half of them became continent and half had rare incontinence afterwards.

Five patients with CBE (three females and two males) had the only BNR as a newborn, when the bladder was initially closed. The females had daily incontinence with volitional voiding at the age of 10 years, but two of them became fully continent and one had rare incontinence after puberty. One male with CBE became continent with volitional voiding before the age of 10 years and the other male underwent bladder augmentation at the age of 10 years. Altogether 35 of our 63 patients had received bladder neck injections. In the cohort of 35 incontinent patients at the age of 10 years, 26 patients had bladder neck injections with Deflux ${ }^{\circledR}$, with 11 patients having the injections before the age of 10 years and the remaining 15 patients got last injections after that. Among the latter 15 patients three males (one with CBE and two with epispadias) became continent after the injections and in other three patients daily incontinence changed to rare incontinence. 
The latest control for the patients was at median age of 19 years (IQR 17-21 years). Nineteen patients had undergone bladder augmentation. Of these one male and one female underwent bladder augmentation after puberty because of persisting incontinence. In addition, two continent females with $\mathrm{CBE}$ were on a regular $\mathrm{CIC}$ and one continent male CBE patient has started CIC program once a day. Twenty-five $(40 \%)$ of all 63 patients have been continent with volitional voiding (11/38 (29\%) with CBE and 14/25 (56\%) with epispadias, $p=0.039)$. In addition, eight (13\%) patients (1/38 (3\%) with CBE and 7/25 (28\%) with epispadias) have rare incontinence usually with small leaks mostly if the bladder is over distended or during sports. Socalled social continence (continence or rare incontinence) with volitional voiding was achieved in 12 of 37 (32\%) CBE patients and in 21 of 26 (81\%) epispadias patients $(p=<0.01)$. There was no statistical difference between males and females neither among CBE or epispadias patients (5/21 (24\%) vs. 7/16 (44\%) and 17/19 (89\%) vs $4 / 7(57 \%)$ respectively, $p=0.28$ and 0.10$)$ (Fig. 2 ). Of those eight who have daily incontinence, three patients leaks mainly droplets during a day necessitating the use of one pad per day. 


\section{DISCUSSION}

Among our patients $28 \%$ with CBE and $56 \%$ with epispadias have become continent with volitional voiding in young adulthood. Forty percent of them reached continence during pubertal development without major surgery. Of the remainder, $13 \%$ had rare incontinence episodes with volitional voiding. Probability for development of continence during puberty was better among patients not having daily incontinence. Pubertal development promoted continence both in male and female CBE patients as well as in male epispadias patients. In few cases, bladder neck injections may have influenced this positive development during puberty.

In the previous studies, there is a wide variation in continence results in CBE and epispadias patients depending on the definition of continence, age at evaluation and surgical treatment protocol ${ }^{2}$. Some studies suggest that more than $70 \%$ of the patients have achieved daytime urinary continence with normal voiding at a very young age ${ }^{9,10}$. However, in a very recent large study from USA only $25 \%$ of the CBE patients were expected to be continent with normal voiding per urethra ${ }^{8}$. The result was very similar as in a previous French and UK studies ${ }^{3,11}$. The most common definition for continence is a dry interval greater than three hours ${ }^{5}$. According to this definition, $32 \%$ of our CBE patients and $81 \%$ of our epispadias patients were socially continent with volitional voiding as young adults. We have earlier shown that the result of continence is greatly related to the definition for continence ${ }^{12}$. In that series, three-hour continence was noted in 54\% of adult CBE and epispadias patients who were voiding normally, but the result decreased to $17 \%$ if any incontinence in structured DAN-PSS questionnaire was noticed. Possibility for bladder augmentation has been discussed with incontinent patients, but they rather 
keep diapers than perform $\mathrm{CIC}$ despite of national health insurance covering the operation almost fully and the catheters fully.

Bladder outlet obstruction after BNR is a known phenomenon and it can lead to detrusor failure or impairment of bladder compliance and stability ${ }^{13,14}$. Recent study from USA supported this, as majority of the CBE patients needed bladder augmentation within 10 years after BNR ${ }^{15}$. Only $14 \%$ of adult CBE patients did not need to perform $\mathrm{CIC}$ as there was increasing need for augmentation during puberty $^{15}$. Also in our previous study with adult CBE and epispadias patients, as well as in previous French study with CBE patients, majority of patients without bladder augmentation had disturbing symptoms related with poor bladder emptying ${ }^{3,12}$. It is possible that some more of our patients will need CIC or bladder augmentation later in adulthood, because of poor bladder emptying and small bladder volume of noncompliant bladder.

We can only speculate the reasons for pubertal development of continence in our patients. Apparently, sex hormones have impact on lower urinary tract in puberty ${ }^{16}$. Undoubtedly, the voiding habits may develop along with emotional maturation and with the help of rigorous voiding program during puberty, especially in patients with rare incontinence. In them, the leaks often associate with bladder overfilling in special situations. However, some of the patients had severe incontinence before puberty and possibility of bladder augmentation was discussed before development of spontaneous continence. 
Our study has several limitations. Evaluation of pubertal development of continence is based on selected patient material, since the patients who had undergone bladder augmentation before the age of 16 years were excluded from the analysis. If all patients had been without augmentation surgery, the percentage of those who did not become continent during puberty had been lower. Because of the retrospective nature of the study, it was not possible to assess the quantity of incontinence properly in many patients. However, occurrence and frequency of any incontinence was reported rather well. The patient groups are small and it is not possible to make proper statistical comparisons, but our material is representative in national level, since almost all Finnish patients with CBE and epispadias are treated in our hospital. In addition, almost all patients had regular follow-up program yearly or every second year.

\section{CONCLUSIONS}

We conclude that approximately half of incontinent CBE and epispadias patients without CIC can achieve continence during pubertal development. The prognosis was especially good in patients with rare incontinence and male epispadias. Accordingly, bladder augmentation should be postponed at least in patients without total incontinence. 


\section{REFERENCES}

1. Gargollo PC, Borer JG: Contemporary outcomes in bladder exstrophy. Curr Opin Urol 2007;17:272-280.

2. Promm M, Roesch WH. Recent Trends in the Management of Bladder Exstrophy: The Gordian Knot Has Not Yet Been Cut. Front Pediatr. 2019 Mar 29;7:110. doi: 10.3389/fped.2019.00110. eCollection 2019. Review

3. Mouriquand PD, Bubanj T, Feyaerts $A$, Jandric M, Timsit M, Mollard P, Mure PY, Basset T. Long-term results of bladder neck reconstruction for incontinence in children with classical bladder exstrophy or incontinent epispadias. BJU Int 2003; 92: 997-1001

4. Capolicchio G, McLorie GA, Farhat W, Merguerian PA, Bägli DJ, Khoury AE. A population based analysis of continence outcomes and bladder exstrophy. J Urol 2001 ; 165: 2418-21

5. Lloyd JC, Spano SM, Ross SS, Wiener JS, Routh JC. How dry is dry? A review of definitions of continence in the contemporary exstrophy/epispadias literature. J Urol 2012;188:1900-4. doi: 10.1016/j.juro.2012.07.017.

6. Lottmann HB, Margaryan M, Lortat-Jacob S, Bernuy M, Läckgren G. Longterm effects of dextranomer endoscopic injections for the treatment of urinary incontinence: an update of a prospective study of 61 patients. J Urol. 2006;176:1762-6. doi: 10.1016/j.juro.2006.03.121.

7. Pakkasjärvi N, Taskinen S. Does intraoperative success predict outcome in the treatment of urethral sphincter insufficiency with bulking agent? J Pediatr Urol. 2018;14:173.e1-173.e5. doi: 10.1016/j.jpurol.2017.10.020.

8. Maruf M, Manyevitch R, Michaud J, Jayman J, Kasprenski M, Zaman MH, Benz K, Eldridge M, Trock B, Harris KT, Wu WJ, Di Carlo HN, Gearhart JP. 
Urinary Continence Outcomes in Classic Bladder Exstrophy: A Long-Term Perspective.

J Urol. 2020;203:200-5. doi: 10.1097/JU.0000000000000505.

9. Chan DY, Jeffs RD, Gearhart JP. Determinants of continence in the bladder exstrophy population: predictors of success? Urology $2001 ; 57: 774-7$

10.Shnorhavorian M, Grady RW, Andersen A, Joyner BD, Mitchell ME. Longterm followup of complete primary repair of exstrophy: the Seattle experience. J Urol. 2008;180:1615-1619; discussion 1619-20. doi:

10.1016/j.juro.2008.04.085.

11. Dickson AP. The management of bladder exstrophy: the Manchester experience. J Pediatr Surg. 2014;49:244-50. doi:

10.1016/j.jpedsurg.2013.11.031.

12. Taskinen S, Suominen JS. Lower urinary tract symptoms (LUTS) in patients in adulthood with bladder exstrophy and epispadias. BJU Int. 2013 Jun;111(7):1124-9. doi: 10,1111/j.1464-410X.2012.11756.x.

13. Woodhouse CR, Redgrave NG. Late failure of the reconstructed exstrophy bladder. Br J Urol. 1996;77:590-2.

14. Diamond DA, Bauer SB, Dinlenc C, Hendren WH, Peters CA, Atala A, Kelly M, Retik AB. Normal urodynamics in patients with bladder exstrophy: are they achievable? J Urol. 1999;162:841-4; discussion 844-5.

15.Szymanski KM, Fuchs M, Mcleod D, Rosoklija I, Strine AC, VanderBrink B, Whittam B, Yerkes E, Gargollo PC; Pediatric Urology Midwest Alliance (PUMA). Probability of Bladder Augmentation, Diversion and Clean Intermittent Catheterization in Classic Bladder Exstrophy: A 36-Year, Multi- 
Institutional, Retrospective Cohort Study. J Urol. 2019;202:1256-62. doi:

10.1097/JU.0000000000000552.

16. Abelson B, Sun D, Que L, Nebel RA, Baker D, Popiel P, Amundsen CL, Chai T, Close C, DiSanto M, Fraser MO, Kielb SJ, Kuchel G, Mueller ER, Palmer MH, Parker-Autry C, Wolfe AJ, Damaser MS. Sex differences in lower urinary tract biology and physiology. Biol Sex Differ. 2018;9:45. doi: 10.1186/s13293-0180204-8. 


\section{Figure legends}

Fig.1 Flow chart of the patients.

Fig. 2 Continence situation in patients operated for classic bladder exstrophy or epispadias in the last control. 
Table 1. Development of continence during puberty according to sex and diagnosis in 31 incontinent patients with volitional voiding and without major surgery.

\begin{tabular}{lcc|ccc} 
& \multicolumn{2}{c|}{ Age of 10 years } & \multicolumn{3}{c}{ After puberty } \\
& Rare Inco & Daily Inco & Continent & Rare Inco & Daily Inco \\
\hline Male CBE & 1 & 8 & 3 & 0 & 6 \\
Male epispadias & 7 & 6 & 10 & 2 & 1 \\
Female CBE & 0 & 5 & 3 & 1 & 1 \\
Female epispadias & 0 & 4 & 0 & 2 & 2
\end{tabular}


Figure 1

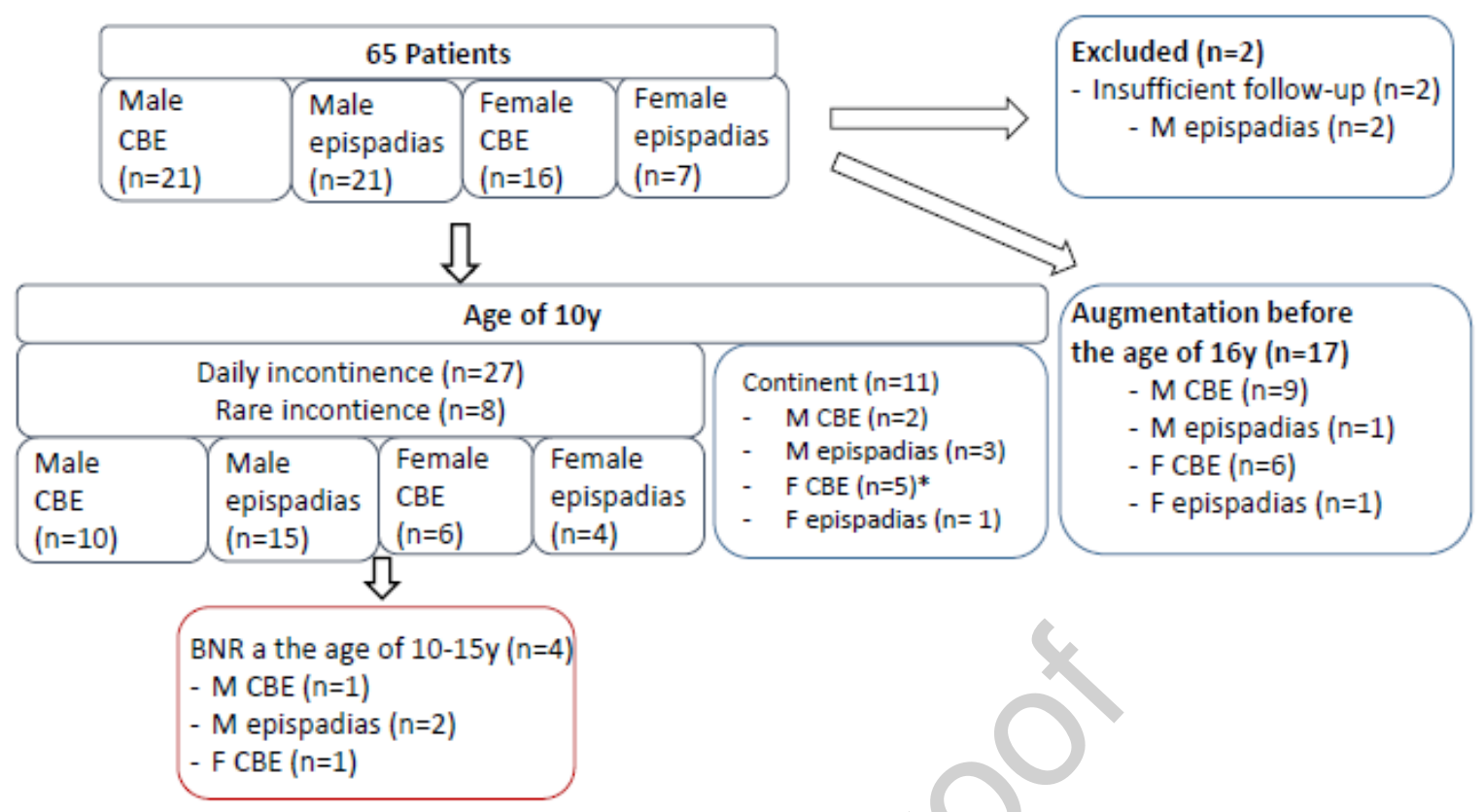


Figure 2

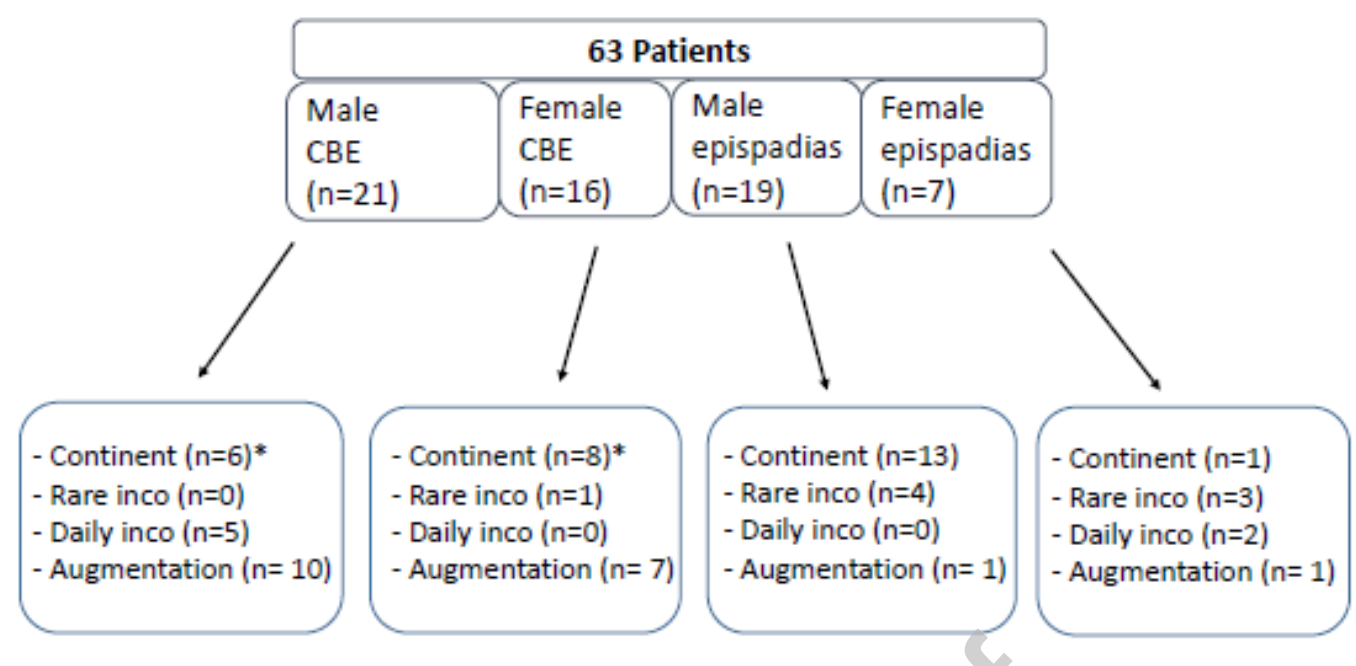

*One male on CIC once a day and two females on regular CIC 